Please do not remove this page

RMIT

UNIVERSITY

\title{
Implementing backcasting for conservation: Determining multiple policy pathways for retaining future targets of endangered woodlands in Sydney, Australia
}

Gordon, Ascelin

https://researchrepository.rmit.edu.au/esploro/outputs/9921862174701341/filesAndLinks?institution=61RMIT_INST\&index=null

Gordon, A. (2015). Implementing backcasting for conservation: Determining multiple policy pathways for retaining future targets of endangered woodlands in Sydney, Australia. Biological Conservation, 181, 182-189. https://doi.org/10.1016/j.biocon.2014.10.025

Document Version: Accepted Manuscript

Published Version: https://doi.org/10.1016/j.biocon.2014.10.025

Repository homepage: https://researchrepository.rmit.edu.au

(C) 2014 Elsevier Ltd.

Downloaded On 2023/04/26 19:34:18 +1000 
Thank you for downloading this document from the RMIT Research Repository.

The RMIT Research Repository is an open access database showcasing the research outputs of RMIT University researchers.

RMIT Research Repository: http://researchbank.rmit.edu.au/

\section{Citation:}

Gordon, A 2015, 'Implementing backcasting for conservation: Determining multiple policy pathways for retaining future targets of endangered woodlands in Sydney, Australia', Biological Conservation, vol. 181, pp. 182-189.

See this record in the RMIT Research Repository at: https://researchbank.rmit.edu.au/view/rmit:30048

Version: Accepted Manuscript

Copyright Statement: (c) 2014 Elsevier Ltd. This work is licensed under a Creative Commons Attribution-NonCommercial-NoDerivatives 4.0 International License.

Link to Published Version:

http://dx.doi.org/10.1016/j.biocon.2014.10.025

\section{PLEASE DO NOT REMOVE THIS PAGE}




\title{
Implementing backcasting for conservation: Determining multiple policy pathways for retaining future targets of endangered woodlands in Sydney, Australia
}

\author{
Ascelin Gordon ${ }^{\mathrm{a}, *}$ \\ ${ }^{a}$ School of Global Urban and Social Studies, RMIT University, GPO Box 2476 \\ Melbourne 3001, Australia. \\ ${ }^{*}$ Corresponding author. Tel.: +61 399259930. \\ E-mail address: ascelin.gordon@rmit.edu.au
}

Note this article has been published as:

Gordon A. (2015) Implementing backcasting for conservation: determining multiple policy pathways for retaining future targets of endangered woodlands in Sydney, Australia. Biological Conservation. 181: 182-189. doi:

10.1016/j.biocon.2014.10.025

\begin{abstract}
Developing conservation policy is a challenging process, often impeded by a lack of clear objectives and a limited understanding of the pathways to achieve them. Here, the utility of target-based 'backcasting' is demonstrated for developing effective conservation policies. Backcasting encodes social values by requiring a desired future state be selected as a target; it then involves searching for multiple pathways to reach this state from the present. This approach is demonstrated with a case study examining policy options for mitigating impacts from the growth of Sydney on a critically endangered woodland community. A model was developed to predict changes in woodland area over time in response to a range of processes: declines in habitat condition; legal and illegal clearing for development; and the implementation of biodiversity offsets to compensate for clearing. Using a target of retaining $60 \%$ of the current woodland distribution in 50 years time, the backcasting analysis involved searching for all combinations of processes that would achieve this target. Results demonstrate how backcasting provides a structured way to explore the trade-offs and robustness of combinations of policy interventions leading to a desirable future. For this case study, the most viable way of achieving the target may be to ensure the offset policy is adequate and enforced. If this was not feasible, the analysis shows that reducing the rate at which habitat is declining in condition would be most important in opening up other policy options. This study provides the first quantitative demonstration of backcasting in a conservation context.
\end{abstract}

Key words: Backcasting; biodiversity offsets; conservation policy; Cumberland plain woodland; habitat degradation; urban development 


\section{Introduction}

A pervasive problem in the global attempts to conserve biodiversity is evaluating the extent to which conservation focused policies achieve their goals (Bennear and Coglianese, 2005; Ferraro and Pattanayak, 2006). There are many reasons why this poses such a challenge, including factors internal to the policy development cycle such as poorly defined objectives or a lack of political will for accountability (Ferraro and Pattanayak, 2006). External factors pose an even greater challenge and include the temporal delays between policy interventions and on-ground outcomes, uncertainties in the baseline data from which to measure performance and a lack of resources to monitor outcomes at appropriate temporal and spatial scales (Bull et al., 2014; Bottrill et al., 2011; Griscomb et al., 2009).

Together, these factors complicate the policy development cycle and often result in traditional ex-post evaluations of policy outcomes being unfeasible. They also add considerable uncertainty in determining how existing conservation-focused policies should be refined, or how new policies should be structured. A number of approaches have been proposed to help address these issues including scenario analysis, adaptive approaches and resilience thinking (Peterson et al., 2003; Groves and Lempert, 2007; Polasky et al., 2011). Here, it is proposed that 'backcasting' is added to this list as a complementary and under-utilised approach for supporting the development of effective conservation policies.

'Backcasting' has different meanings across fields of science and was first used as an alterative to forecasting in the early 1980s for developing energy policy (Robinson, 1982). However the origins of backcasting go back further to the 1970s when Amory Lovins proposed a 'backwards-looking-analysis' to overcome difficulties in long-term energy forecasting (Robinson, 1982). An interesting aspect of backcasting is that it is an explicitly normative approach in that it involves defining a desired future state as a target, and then determining multiple pathways to traverse from the current state to the future state (Dreborg, 1996). It can be thought of as temporally opposite to forecasting, which involves extrapolating current trends and is often used with scenario analysis (Cinq-Mars and Wiken, 2002). One of the strengths of the backcasting approach is that it is explicitly based on searching out multiple pathways to meet future objectives, and can thus encourage a broader view of relevant factors, leading to the systematic consideration of options that may not otherwise be considered 'feasible' (Manning et al., 2006).

There have been numerous interpretations of backcasting (Holmberg, 1998; Höjer and Mattsson, 2000; Vergragt, 2005) and although the technique has significant potential in a conservation context, its use to date has been limited and qualitative. These qualitative approaches have proposed using backcasting for planning ambitious restoration projects (Manning et al., 2006), as a tool for participatory scenario 
planning (Palomo and Montes, 2011) and for determining general incentives for ecosystem conservation (Cinq-Mars and Wiken, 2002).

Here, a quantitative example of target-orientated backcasting (Wangel, 2011) is presented (henceforth referred to as "backcasting") using a case study examining policy development to mitigate biodiversity impacts from the growth of Sydney, Australia. The utility of backcasting is demonstrated in a modelling context by exploring multiple policy options likely to meet future conservation targets for retaining critically endangered woodlands on the Cumberland Plain to the west of Sydney.

\section{Methods}

\subsection{Study area}

The Cumberland Plain Shale Woodlands and Shale-Gravel Transition Forest ecological community (henceforth referred to as "CPW") occurs primarily to the west of Sydney, in the state of New South Wales (NSW), Australia. This threatened ecosystem has been extensively cleared for agriculture and urban development. Its pre-1750 coverage was estimated to be 125,450 ha, and now 9\% (10726 ha) of this original area is estimated to remain (State of New South Wales, 2011). Less then 10\% of the current CPW extent is represented in formal conservation reserves with the remainder occurring predominantly on private land (State of New South Wales, 2011). As the CPW community is now listed as "critically endangered" under the Australian Government's Environment Protection Biodiversity Conservation (EPBC) Act (Commonwealth of Australia, 2009), actions impacting the community are only subject to approval under specific conditions.

To meet Sydney's projected population growth, expansions of two Urban Growth Centres are planned, which includes the development of areas that will result in clearing significant amounts of CPW over the next 30 years (State of New South Wales, 2010). To compensate this loss, "biodiversity offsets" (Bull at al., 2013) will be implemented inside and outside the Growth Centres, resulting in CPW being protected and managed. The intention behind the offsets is that the gains in ecological condition and the avoided clearing of CPW will "offset" the clearing of CPW for urban development (Gordon et al., 2011). These offsets are required under both NSW state legislation (State of New South Wales, 2010) and the EPBC Act (Commonwealth of Australia, 2012). Additional background is given in Appendix A.

In addition to urbanisation, there are other threats to the remaining CPW. The most significant being legal and illegal clearing of vegetation outside the Growth Centres and the decline in ecological condition of the community due primarily to invasive plant species such as the African Olive and African Love Grass (State of New South Wales, 2011). 


\subsection{Modelling the change in $C P W$ over time}

A model developed to predict changes in CPW extent over time was written in python using a new open source modelling framework entitled Tzar (Gordon et al., 2013). Construction and parameterisation of the model was undertaken by utilising the expert opinion and data obtained from relevant experts within in two Australian Government Departments: the Environment Assessment and Compliance Division of the Federal Department of the Environment, and the NSW Office of Environment and Heritage. Further details are given in Appendix A.

The model predicts changes in the total area of CPW over time for the next 50 years in one-year time steps and incorporates the development and offset processes. Six land-use categories were used in the model (Table 1), and these categories determined where clearing and offsets could occur and how the condition of the CPW would change. The initial areas of CPW in each land-use category are given in Table A2 of Appendix A.

The scenario modelled here meets requirements for both NSW State legislation and Federal legislation (the EPBC Act). For each parcel developed the EPBC Act allows for half the CPW on the parcel to be cleared, provided an offset comprising twice the area of the cleared $\mathrm{CPW}$ is implemented. As the remaining $\mathrm{CPW}$ on the parcel can count towards this offset, a parcel with an area $A$ of CPW can have $A / 2$ cleared with an offset consisting of $A / 2$ retained on the parcel and $A / 2$ of CPW protected outside the Growth Centres. The relevant NSW state legislation is the State Environmental Planning Policy (SEPP; State of New South Wales, 2006). Over the next 30 years the SEPP and the EPBC Act together allow 594 ha CPW to be cleared within Growth Centres. The SEPP specifies that 518 ha CPW will be included as offsets within the Growth Centres and an additional 594 ha of CPW need to be implemented outside the Growth Centres to meet the EPBC Act offset requirements.

\subsubsection{Modelling declines in $C P W$ condition}

Although there are good estimates of the current extent of CPW (NSW Scientific Committee \& Simpson, 2008), there is limited information about its current condition or the rate at which its condition is declining. As there is strong evidence (State of New South Wales, 2011) combined with expert opinion that habitat decline is occurring, a habitat decline process was included in the model. Due the lack of information, no assumptions were made about the condition dynamics of any of the CPW apart from the fact that each year a fixed proportion, $d$, degrades to a level where it is no longer classified as CPW (or where it is not economically viable to restore; Table 2). Apart from the protected and offset land uses where CPW is assumed to be managed (Table 1), all remaining CPW is subject to this decline. For an area of unmanaged CPW, $A$, the decline of CPW in time step $t+1$ is given by

$$
A_{t+1}=A_{t}-d \times A_{t}, \quad 0 \leq d \leq 0.02
$$


Expert estimates of the upper plausible bound of parameter $d$ was 0.02 , resulting in a loss of $2 \%$ of the unmanaged CPW per year (Table 2). The actual value for $d$ will depend on both the distribution of the current condition of the patches of CPW, as well as the rate at which they are degrading. This approach is effectively modelling the lower tail of the condition distribution, where $d$ determines that rate at which CPW “drops off” from being in low condition to no longer being assumed to be CPW.

\subsubsection{Modelling clearing and offsets}

The loss of CPW each time step is given by two terms: $A_{t}^{d e v, o G C}$ and $A_{t}^{d e v, i G C}$ representing the area of CPW cleared outside and inside the Growth Centres, respectively. $A_{t}^{d e v, o G C}=c$, which can be expanded to

$A_{t}^{d e v, o G C}=p \times c+(1-p) \times c$

while

$A_{t}^{\text {dev }, i G C}=\left\{\begin{array}{ll}19.8 \text { ha/year, } & t \leq 30 \text { years } \\ 0, & t>30 \text { years }\end{array}\right.$.

The 19.8 ha/year in equation 3 results in the 518 ha being cleared over 30 years as per the SEPP (see Section 2.2). In equation 2, $c$ is the clearance rate parameter controlling the area of CWP cleared outside the Growth Centres (Table 2), with $p$ determining the proportion that is legal and $(1-p) \times c$ representing the area of illegal clearing that does not result in offsets.

The resulting offsets from this clearing are then implemented inside the Growth Centres as

$A_{t}^{o, i G C}=\left\{\begin{array}{ll}17.3 \text { ha/year, }, & A_{t}^{d e v, i G C}>0 \\ 0, & A_{t}^{d e v, i G C}=0\end{array}\right.$,

and outside the Growth Centres as

$A_{t}^{o, o G C}= \begin{cases}m \times p \times c+19.8 \mathrm{ha}, & \left(A_{t}^{d e v, o G C}>0\right) \wedge\left(A_{t}^{d e v, i G C}>0\right) \\ m \times p \times c, & \left(A_{t}^{d e v, o G C}>0\right) \wedge\left(A_{t}^{d e v, i G C}=0\right) \\ 19.8 \mathrm{ha}, & \left(A_{t}^{d e v, o G C}=0\right) \wedge\left(A_{t}^{d e v, i G C}>0\right) \\ 0, & \left(A_{t}^{d e v, o G C}\right)=0 \wedge\left(A_{t}^{d e v, i G C}=0\right)\end{cases}$

where " $\wedge$ " represents logical "AND". Thus offsets are only implemented when development can occur. The annual offsets of 17.3 ha and 19.8 ha are fixed requirements from development inside the Growth Centres, $m$ is the offset multiplier (Table 1) and $p \times c$ is the proportion of legally cleared CPW outside the Growth Centres. 


\subsubsection{Full model of change in CPW over time}

Using the definitions above, the model describing the change in CPW over time can be expressed as:

$A_{t=0}=10726$ ha

$A_{t+1}=\sum_{i}^{D_{t}}\left(A_{t}^{i}-d \times A_{t}^{i}\right)+\sum_{j}^{P_{t}}\left(A_{t}^{j}\right)-A_{t}^{\text {dev,iCG }}-A_{t}^{\text {dev,oGC }}$

were equation 6 specifies the initial amount of CPW. The first term in equation 7 is the loss from decline in habitat condition (equation 1), the second term is the CPW retained and managed (equations $4-5$, resulting from a land use change from offsettable to offset and existing protected land; Table 2), and the third and fourth terms are the losses of CPW due to clearing (equations $2-3$, resulting from a land use change from developable to developed; Table 1). In the first term in equation 7, $D_{t}$ $=\{$ secured, undevelopable, developable, offsettable $\}$ and represents the land uses where $\mathrm{CPW}$ can degrade while in the second term $\mathrm{P}_{t}=$ \{protected, offset $\}$, and represents the land uses where CPW is managed. Both $D_{t}$ and $P_{t}$ are indexed by time, indicating the area in each of these categories can change over time as specified in equations $2-5$.

The full specification of the model involves more complex constraints than shown here for equations 2 and 3, and the full constraints are provided in Appendix A (Section A.2.3). This is because clearing and offsetting can only occur if enough CPW is available in the appropriate land uses for both processes. At some point in the simulation the remaining CPW can become "locked up"-all being either lost or protected - at which point no further development and offsetting can occur. If and when this occurs depends on the particular values of the policy parameters.

\subsection{Backcasting}

The planned clearing within the Growth Centres (and associated offsets) are assumed to be fixed impacts that always occur. The other major threats of condition decline and the legal and illegal clearing of CWP outside the growth centres were controlled by the four parameters given above: the degradation rate $(d)$, clearance rate $(c)$, proportion of clearing requiring offsets $(p)$ and the offset multiplier $(m)$ (Table 2$)$ ). As a range of real-world policy interventions could alter the processes represented by these parameters, they are henceforth referred to as the policy parameters.

To capture both uncertainty in the current value of the policy parameters $d, c, p, m$ and to explore the impact of a range of future conservation policies, each of the parameters was varied in steps between its plausible maximum and minimum values (Table 2; see Table A1 in the Supplementary Information for further details). The model was then run with every possible parameter value combination. This created an ensemble $E$, consisting of 11,616 model realizations, with each member, $i$, of $E$ 
represented as a function describing the change in CPW over time, and is indexed by the values of each of the four policy parameters used to generate it: $A_{t}\left(d_{i}, c_{i}, p_{i}, m_{i}\right)$.

To apply the backcasting approach, a future target was defined as $A_{50} \geq T$, where $A_{50}$ is the predicted area of CPW remaining in fifty years time, and $T$ is the target area to retain. Selecting an ensemble $S$ which is a subset of $E$ (i.e. $S \subseteq E$ ) such that for every member $j$ of $S$,

$A_{50}\left(d_{j}, c_{j}, p_{j}, m_{j}\right) \geq T$

gives the combinations of input parameter values, and therefore the regions of the 'policy parameter space', predicted to retain at least the target area of CPW.

Even though the ensemble $S$ is a subset of $E$, it still can contain thousands of members. Thus it is helpful to cluster the members into an operationally useful number of 'policy options', with each corresponding to a different region of the policy parameter space. One useful way of achieving this is via a classification tree analysis (Breiman et al., 1984). This builds a 'tree' by splitting the data using simple rules into branch-like segments (nodes), which best predict the value of a discrete dependent variable from a set of independent variables. In this case the dependent variable is binary and represents whether or not the CPW retention target was met and the independent variables are the four policy parameters. As all nodes have mutually exclusive assignment rules, there is a unique 'rule set' associated with each node, which consists of constraints on the values of the policy parameters. This allows the terminal nodes to be considered different policy options. The classification tree analysis was undertaken using the rpart package in version 3.1.0 of $\mathrm{R}$ (Therneau et at., 2014; R Core Team, 2014) and the R source code for the analysis is provided in Appendix B.

\section{Results}

Each model realization with one of 11,616 parameter combinations potentially resulted in a different area of CPW remaining. Fig. 1 shows the distribution of the remaining CPW after 50 years for all model realizations as a percentage of the pre$1750 \mathrm{CPW}$ extent. It has a mean of $4.8 \%$, with minimum of $2.8 \%$ and a maximum of $7.1 \%$. To illustrate the backcasting approach, a target area of CPW comprising $60 \%$ of the current distribution at the fiftieth year was chosen, which corresponds to $5.1 \%$ of the estimated original CWP extent. The target is depicted in Fig. 1 as a vertical grey line and there were 4637 parameter combinations that met or exceeded the target. Thus the subset ensemble, $S$, comprises 4637 members, which corresponds to $40 \%$ of the total number in $E$. Any target could be used for this type of analysis and using a higher (or lower) target resulted in a reduced (or increased) number of policy options compared to the results shown below. 
The 4637 members of $S$ comprise the essence of the backcasting approach as they define many different combinations of the policy parameters likely to result in the backcasting target being met. Yet it is a significant challenge to be able to interpret these 4637 members in an operationally useful way. To overcome this, the classification tree analysis was applied using the four policy parameters $(d, c, p, m)$ as the dependant variables. This produces a tree with 12 terminal nodes (Fig. 2), each of which has between two and five splits on the policy parameters. The set of constraints associated with a terminal node can be labelled a "rule set" and the terminal nodes labelled "TRUE" or "FALSE" in Fig. 2 correspond to the rule sets that predominantly meet, or fail to meet the target, respectively. The rule sets associated the six terminal nodes labelled TRUE in Fig. 2 consist of a set of inequalities (such as $0.35 \leq p \leq 1$ ), which provide a set of constraints on each of the policy parameters. The full rule sets associated with each of the six policy options are shown in Table 3, which also includes brief descriptions of the policy implications of the rule set.

In the same way as a set of inequalities on two variables defines a rectangle in the two-dimensional plane (e.g. $a \leq x \leq b ; c \leq y \leq d$ defines a rectangle with width $b-a$, height $d-c$, and area $(b-a)(d-c))$, the set of constraints associated with each rule set defines a four-dimensional rectangle (or technically a 'hyper-rectangular cuboid'). This cuboid exists in a four-dimensional policy space, where the axes of the space are the four policy parameters. Fig. 3 shows three dimensions of this fourdimensional policy space and Fig. 3(a) shows the distribution of all members of ensemble $S$ to which the classification tree analysis is applied. A more intuitive understanding of the resulting rule sets can be obtained by visualising them in three dimensions, along with the constraint on the unshown fourth parameter. This is shown in Fig. 3(b)-(d) for rule sets 1, 3, 5 and 6 and provides scope for understanding how different policy parameters trade-off against each other in while still allowing for the backcasting target to met.

The 'volume' of each rule set can visualised in three dimensions using this approach (Fig. 3(b)-(d)) and Table 3 lists the volume associated with each rule set in the fourdimensional policy space. There is considerable variation in the volumes of the rule sets, with rule set 1 (the largest) being 55 times greater then the volume of rule set 6 (the smallest; Table 3). It should be noted that this measure of volume is only useful for comparing rule sets, as the absolute value of the volume depends on the units chosen of the policy parameters.

The accuracy of the classification tree analysis varies for the different rule sets but is generally high. This can be seen in Fig. 2 where the number of results that pass or fail the backcasting target are shown for each terminal node. Table 3 also lists the classification accuracy of each rule set, which varies from over $90 \%$ (rule sets $1,2,3$ ) down to $68 \%$ (rule set 6 ). 
The data and scripts written in $\mathrm{R}$ used to create the three figures in this paper are available for download as described in Appendix B.

\section{Discussion}

This study examined the backcasting approach and explored how it provides a useful methodology for determining multiple policy options likely to meet future conservation targets. The results presented here provide the first quantitative demonstration of the use of backcasting in a conservation context, examining how this method can be applied to policies aimed at limiting the impact of the growth of Sydney on a critically endangered woodland ecosystem.

The first point to note is that backcasting is a target-based approach, although it differs from more common target-based approaches in conservation (Carwardine et al., 2009) in that the targets are set for a specific point in the future. Target-based approaches are important in that they require explicit measurable objectives to be articulated at the outset of the analysis. This allows the performance of a policy to be tracked relative to its target(s), which is particularly important in a conservation context where policy outcomes are often effectively irreversible. In some cases it may be important to track of the extent to which a policy option might exceed targets, as this could make that option more desirable, or in some cases less preferable if it results in greater negative impacts on some stakeholders. It should also be noted that changing the target results in different rules sets from the classification tree analysis (and therefore different policy options), which should be expected given higher targets provide greater constraints on the viable policy options. The targets in quantitative backcasting also comprise a normative aspect of the analysis as they incorporate societal values. Having this normative component of the analysis limited to the initial target-setting phase provides greater transparency as it is clear how societal values are influencing the analysis.

Once targets have been specified, the results presented here show one way of exploring multiple paths to achieve them, providing a visually compelling analysis of the different combinations of possible policy interventions, and the trade-offs between them. This approach contrasts with the combination of forecasting and scenario analysis, which focuses on extrapolating current trends under multiple scenarios and therefore focusing of the futures that are most likely, rather then those that are most desirable. In some cases, the composition of realistic scenarios producing a desirable future can be difficult to determine, or at worst may not exist. The fact that backcasting is specifically focused on attempting to find these policies or scenarios is one reason why it provides a useful and complementary approach to other methods.

The exploration of different paths to achieve a given future target can encourage policy makers to consider a broader range of policy options when facing a particular conservation challenge (Manning et al., 2006). In this analysis, examining the relative 
locations of the rectangular cuboids in the policy parameter space (Fig. 3) and the associated rule sets (Table 3), allows a policymaker to obtain a clearer understanding of the different conservation interventions required and the trade-offs between them. For example, in policy option 1, the numerical values listed in Table 3 imply there is no constraint on the offset multiplier or the proportion of clearing requiring offsets, but the degradation rate must be low and the clearance rate must be in the lower half of its plausible range. In a policy context, this means there can be more relaxed offsetting requirements and less stringent controls on illegal clearing, provided work is done to limit the declines in condition from invasive species and that the total amount of clearing outside the Growth Centres is not too high. In contrast, policy option 6 allows the degradation rate to reach its maximum plausible value with the clearance rate in the upper half of its range, but both the offset multiplier and the proportion of clearing requiring offsets must also be in the upper half of their range. In other words, as long as the offset policy is adequate (large enough multiplier) and strictly enforced (only small amounts of illegal clearing), the CPW targets can be met even with high levels of habitat condition decline and large amounts of clearing outside the Growth Centres. The other policy options shown in Table 3 show how the policy parameters trade-off between these two extremes. Thus in this situation the backcasting results provide insight into how rigorously a policy would need to be enforced or the extent to which management actions would need to be undertaken.

When examining particular policy options for retaining CPW, the ability of a policymaker to control the processes underlying each of the policy parameters may vary considerably. At one extreme, the policymaker has a high level of control on the value of the offset multiplier $(m)$, as this is part of the offset policy (though it will be subject to political constraints). At the other extreme is the rate at which the CPW is degrading $(d)$ and the illegal clearing rate (given by $(1-p) \times c$ ) which are characterised by considerable uncertainty regarding the current and future values of $d$ and $p$. In addition, it may be difficult and expensive to undertake the interventions required to alter these processes. This is due to the expense of controlling invasive species and the difficulties of accessing the CPW, which is mostly on private land. Until better information is available on the rate at which the CPW condition is declining across the study area, policies based on rule sets 3 or 6 may be the most robust choices as they allow higher rates of degradation, but with the trade-off being that offset policies have adequate multipliers and are strictly enforced. This analysis also shows that if such a policy was not feasible, reducing the rate of habitat condition decline would be most important in making multiple policy options available (Table 3 ). These points highlight the importance of considering both the costs and feasibility involved with policy interventions. Cost and feasibility could be incorporated into the analysis in a number of different ways. Most simply this could be done by estimating the cost and feasibility values for each policy option, and then ranking options based on this information. Alternatively, cost could be included as an additional axis in the policy parameter space, requiring the cost of each policy intervention to be 
determined. This would allow regions of the space be excluded based on budget constraints, limiting the policy options to only those that were financially viable.

Using a classification tree analysis provides a mechanism for grouping the thousands of potential variations in the conservation interventions into broad groups of policy options that can be more easily interpretable by policymakers. In this case study, the 4637 combinations of policy parameters that met the backcasting target were reduced to 6 general policy options by the classification tree. While the classification generally performed well (Table 3), some parameter combinations satisfying the associated rule set may fall short of the CPW target. This is due to the classification tree not producing perfect classification rules; more accurate classifications could likely be obtained, but these would be at the expense of being easily interpretable with simple rule sets. This is not a significant problem as when a given policy option is chosen as being the most feasible, a more detailed classification could be carried out for the corresponding region of parameter space providing a more complex set of constraints relevant to that specific policy option.

Using the "policy parameter space concept" in the backcasting analysis also has a number of useful features and in particular, the volume of the policy space covered by each option provides useful information (Table 3). This is relevant when considering issues of robustness to uncertainty, which includes uncertainty in the current values of the policy parameters as well as how they might change in response to interventions. From this perspective, policy options with a larger volume in parameter space will allow greater variation in parameter values while still meeting the future target, thus providing greater robustness to uncertainty. Another useful criteria for policymakers to consider is the extent to which a given policy choice closes off future options (Lempert and Collins, 2007). Again, considering the volume in the policy space of a given option is a way of addressing this issue, as options with a greater volume allow a greater variation in parameter values, providing more flexibility in how a policy is structured. These considerations could result in excluding policy option 6 due to its small volume in the policy parameter space.

\section{Conclusion}

Significant challenges remain in developing and implementing conservation policies to halt declines of the natural environment. While backcasting is not a panacea, it provides a useful addition to the conservation policymaker's toolbox, providing a structured way to explore trade-offs between suites of interventions and to identify a multiplicity of pathways to meet desired future targets.

\section{Acknowledgements}

M. Considine, S. Mercer, W.T. Langford provided helpful advice in preparing the analysis presented in this manuscript. R.J. Satya provided invaluable assistance with software development. S.A. Bekessy, G. Garrard, C. Ives, A. Kusmanoff and M. 
Maron and E. McDonald-Madden provided useful feedback on the manuscript. This research was conducted with the support of funding from the Australian Government's National Environmental Research Program.

\section{Supplementary material}

Supplementary data associated with this article can be found, in the online version, at http://dx.doi.org/10.1016/j.biocon.2014.10.025 or by request to the author.

Appendix A. Further details of the predictive model for the future extent of CPW.

Appendix B. Data and R source code to generate figures.

\section{References}

Bennear L.S, Coglianese C. (2005) Measuring Progress: Program Evaluation of Environmental Policies, Environ: Sci.Policy Sustain. Dev., 47, 2, 22-39.

Bottrill, M.C., Hockings, M., Possingham, H.P. (2011). In Pursuit of Knowledge: Addressing Barriers to Effective Conservation Evaluation. Ecol. Soc., 16, 14.

Breiman, L., Friedman, J.H., Olshen, R.A., Stone, C.J. (1984). Classification and Regression Trees. Wadsworth, Belmont.

Bull, J.W., Gordon, A., Law, E., Suttle, K.B., Milner-Gulland, E.J. (2014). Achieving "no net loss" of biodiversity: how the success or failure of conservation interventions depends upon the choice of baseline. Conserv. Biol., 28, 799-809.

Bull, J.W., Suttle, K.B., Gordon, A., Singh, N.J. \& Milner-Gulland, E.J. (2013) Biodiversity offsets in theory and practice. Oryx, 47, 369-380.

Carwardine, J., Klein, C.J., Wilson, K.A., Pressey, R.L., Possingham, H.P. (2009) Hitting the Target and Missing the Point: Target-Based Conservation Planning in Context. Conserv. Lett. 2, 4-11.

Cinq-Mars, J., Wiken, E. (2002). Using science, technology and innovation in support of conserving Canada's ecosystems and habitats. For. Chron., 78, 133136.

Commonwealth of Australia. (2009). Cumberland Plain Shale Woodlands and ShaleGravel Transition Forest. Environment Protection and Biodiversity Conservation Act Species Profile and Threats Database. Available from http://www.environment.gov.au/cgibin/sprat/public/publicshowcommunity.pl?id=112. Accessed 2 September 2013. 
Commonwealth of Australia. (2012) EPBC Act environmental offsets policy. Available from http://www.environment.gov.au/resource/epbc-actenvironmental-offsets-policy Accessed 10 July 2014.

Dreborg, K. (1996). Essence of backcasting. Futures, 28, 813-828.

Ferraro, P.J., Pattanayak, S.K. (2006). Money for nothing? A call for empirical evaluation of biodiversity conservation investments. PLOS Biol., 4, e105.

Gordon, A., Langford, W.T., Satya, R.J., Bastin, L. (2013). Tzar framework. Available from https://tzar-framework.atlassian.net/wiki/. Accessed 4 June 2014.

Gordon, A., Langford, W.T., Todd, J.A., White, M.D., Mullerworth, D.W., Bekessy, S.A. (2011). Assessing the impacts of biodiversity offset policies. Environ. Model. Softw., 26, $1481-1488$.

Griscom, B., Shoch, D., Stanley, B., Cortez, R., Virgilio, N. (2009) Implications of REDD baseline methods for different country circumstances during an initial performance period. Environ. Sci. Policy, 12, 897-911.

Groves, D., Lempert, R.J. (2007). A new analytic method for finding policy-relevant scenarios. Glob. Environ. Chang., 17, 73-85.

Höjer, M., Mattsson, L.-G. (2000). Determinism and backcasting in future studies. Futures, 32, 613-634.

Holmberg, J. (1998). Backcasting: A Natural Step in Operationalising Sustainable Development. Greener Manag. Int., 46, 30-52.

Lempert, R.J., Collins, M.T. (2007). Managing the risk of uncertain threshold responses: comparison of robust, optimum, and precautionary approaches. Risk Anal., 27, 1009-26.

Manning, A.D., Lindenmayer, D.B., Fischer, J. (2006). Stretch Goals and Backcasting: Approaches for Overcoming Barriers to Large-Scale Ecological Restoration. Restor. Ecol., 14, 487-492.

NSW Scientific Committee, Simpson, C. (2008). Change in the distribution of Cumberland Plain Woodland. Unpublished Report.

Palomo, I., Montes, C. (2011). Participatory Scenario Planning for Protected Areas Management under the Ecosystem Services Framework: the Doñana SocialEcological System in Southwestern Spain. Ecol. Soc., 16, 23.

Peterson, G.D., Cumming, G.S., Carpenter, S.R. (2003). Scenario Planning: a Tool for Conservation in an Uncertain World. Conserv. Biol., 17, 358-366.

Polasky, S., Carpenter, S.R., Folke, C., Keeler, B. (2011). Decision-making under great uncertainty: environmental management in an era of global change. Trends Ecol. Evol., 26, 398-404. 
R Core Team (2014). R: A language and environment for statistical computing. $\mathrm{R}$ Foundation for Statistical Computing, Vienna, Austria. http://www.Rproject.org/.

Robinson, J.B. (1982). Energy backcasting A proposed method of policy analysis. Energ. Policy, 10, 337.

State of New South Wales. (2006). State Environmental Planning Policy (Sydney Region Growth Centres) 2006. Available from http://www.legislation.nsw.gov.au/viewtop/inforce/epi+418+2006+cd+0+N/.

Accessed 25 September.

State of New South Wales. (2010). Sydney Growth Centres Strategic Assessment Program Report. Available from http://www .environment.gov.au/epbc/notices/assessments/pubs/sydney-growthcentres-program-report.pdf. Accessed 24 July 2013.

State of New South Wales. (2011). Cumberland Plain Recovery Plan. Available from http://www.environment.nsw.gov.au/resources/threatenedspecies/20100501Cum berlandPlain.pdf. Accessed 13 June 2013.

Therneau, T., Atkinson, B., Ripley B. (2014). rpart: Recursive Partitioning and Regression Trees. $\mathrm{R}$ package version 4.1-8. Available from http://CRAN.Rproject.org/package=rpart. Accessed 13 June 2013.

Vergragt, P.J. (2005). Back-casting for Environmental Sustainability: From STD and SusHouse towards Implementation. Towar. Environ. Innov. Syst., 301-318.

Wangel, J. (2011). Exploring social structures and agency in backcasting studies for sustainable development. Technol. Forecast. Soc. Change, 78, 872-882. 


\section{Tables}

Table 1. A description of the landuse categories used to model the change in area of CPW over time.

\begin{tabular}{|c|c|}
\hline Landuse category & Description \\
\hline Protected & $\begin{array}{l}\text { Existing conservation reserves, not available for clearing. } \\
\text { CPW assumed managed and the habitat condition of CPW } \\
\text { occurring here does not decline over time. }\end{array}$ \\
\hline Secured & $\begin{array}{l}\text { Land owned by the Commonwealth Government, not } \\
\text { available for clearing. CPW assumed unmanaged and the } \\
\text { condition of CPW occurring here does decline. }\end{array}$ \\
\hline Undevelopable & $\begin{array}{l}\text { Land inside the Growth Centres that cannot be cleared or } \\
\text { offset (such as flood prone areas). CPW assumed } \\
\text { unmanaged and condition of CPW occurring here does } \\
\text { decline. }\end{array}$ \\
\hline Developable/Developed & $\begin{array}{l}\text { Land that is available for clearing (unmanaged, CPW } \\
\text { condition declines)/has been cleared for development } \\
\text { (CPW is removed). }\end{array}$ \\
\hline Offsettable/Offset & $\begin{array}{l}\text { Land that is available for offsets (unmanaged, CPW } \\
\text { condition declines)/land that has been used as an offset and } \\
\text { the CPW is assumed managed and does not decline in } \\
\text { condition. }\end{array}$ \\
\hline
\end{tabular}


Table 2. Description on the four policy parameters used in the model. The parameter range specifies the upper and lower plausible values estimated by available evidence and/or expert opinion (Table A1, Appendix A). The step size indicates the size of the increment used to iterate over parameter values between the upper and lower plausible bounds.

\begin{tabular}{|c|c|c|c|c|}
\hline Parameter name & Symbol & Description & $\begin{array}{l}\text { Parameter } \\
\text { range }\end{array}$ & Step size \\
\hline Degradation rate & $d$ & $\begin{array}{l}\text { Yearly proportion of } \\
\text { CPW that declines in } \\
\text { quality to a level where } \\
\text { rehabilitation is } \\
\text { considered unviable. }\end{array}$ & $0-0.02$ & 0.002 \\
\hline Clearance rate & $c$ & $\begin{array}{l}\text { Yearly area of CPW } \\
\text { cleared (legally and } \\
\text { illegally) outside growth } \\
\text { centres. }\end{array}$ & $\begin{array}{l}20-75 \\
\text { ha/year }\end{array}$ & 5 \\
\hline $\begin{array}{l}\text { Proportion of } \\
\text { clearing requiring } \\
\text { offsets }\end{array}$ & $p$ & $\begin{array}{l}\text { Proportion of CPW } \\
\text { outside the Growth } \\
\text { Centres that is legally } \\
\text { cleared and results in } \\
\text { biodiversity offsets. }\end{array}$ & $0-1$ & 0.1 \\
\hline Offset multiplier & $m$ & $\begin{array}{l}\text { Offset area multiplier } \\
\text { required for CPW cleared } \\
\text { outside the Growth } \\
\text { Centres (e.g. } m=2 \\
\text { means that } 4 \text { ha of CPW } \\
\text { is required to be protected } \\
\text { for every } 2 \text { ha cleared). }\end{array}$ & $0.5-4$ & 0.5 \\
\hline
\end{tabular}


Table 3. The six rule sets associated with each of the policy options from the classification tree analysis (Fig. 2). prob is a measure of classification accuracy representing the proportion of parameter combinations consistent with the rule set that meet the backcasting target; vol is the volume of the rule set in 4-dimensional policy parameter space; "denotes the upper or lower plausible bound used in the analysis (i.e. no constraint).

\begin{tabular}{|c|c|c|}
\hline $\begin{array}{c}\text { Policy option } \\
\text { and } \\
\text { summary } \\
\text { information }\end{array}$ & Rule set & Description \\
\hline $\begin{array}{l}\mathbf{1} \\
\text { prob }=0.947 \\
\text { vol }=0.55\end{array}$ & $\begin{array}{l}{ }^{*} 0 \leq d<0.007 \\
{ }^{*} 20 \leq c<42.5\end{array}$ & $\begin{array}{l}\text { No constraint on multiplier or } \\
\text { the proportion of clearing } \\
\text { requiring offsets. The } \\
\text { degradation rate must be low } \\
\text { and clearance rate has to be in } \\
\text { bottom half of range. }\end{array}$ \\
\hline $\begin{array}{l}2 \\
\text { prob }=0.95 \\
\text { vol }=0.41\end{array}$ & $\begin{array}{c}{ }^{*} 0 \leq d<0.007 \\
42.5 \leq c \leq 75^{*} \\
0.35 \leq p \leq 1^{*} \\
1.25 \leq m \leq 4^{*}\end{array}$ & $\begin{array}{l}\text { The degradation rate must be } \\
\text { low, the clearance rate can be } \\
\text { high but the multiplier needs } \\
\text { to be } \geq 1.25 \text {, and the } \\
\text { proportion of clearing having } \\
\text { offsets must be } \geq 0.35 \text {. }\end{array}$ \\
\hline $\begin{array}{l}3 \\
\text { prob }=0.90 \\
\text { vol }=0.27\end{array}$ & $\begin{array}{c}0.007 \leq d \leq 0.015 \\
0.65 \leq p \leq 1^{*} \\
2.25 \leq m \leq 4^{*}\end{array}$ & $\begin{array}{l}\text { A higher degradation rate is } \\
\text { allowed and there is no } \\
\text { constraint on clearance rates. } \\
\text { The multiplier must be } \geq 2.25 \\
\text { and the proportion of clearing } \\
\text { having offsets must be } \geq 0.65 \text {. }\end{array}$ \\
\hline $\begin{array}{l}4 \\
\text { prob }=0.78 \\
\text { vol }=0.092\end{array}$ & $\begin{array}{c}{ }^{*} 0 \leq d<0.003 \\
42.5 \leq c \leq 67.5 \\
{ }^{*} 0 \leq p<0.35\end{array}$ & $\begin{array}{l}\text { If degradation rate is kept low } \\
(<0.3 \%) \text { then clearance rate } \\
\text { can be medium-high, there is } \\
\text { no constraint on the multiplier } \\
\text { and the proportion of clearing } \\
\text { requiring offsets must be } \\
<0.35 \text {. }\end{array}$ \\
\hline $\begin{array}{l}\mathbf{5} \\
\text { prob }=0.69 \\
\text { vol }=0.048\end{array}$ & $\begin{array}{c}{ }^{*} 0 \leq d<0.003 \\
42.5 \leq c \leq 75^{*} \\
0.35 \leq p \leq 1^{*} \\
{ }^{*} 0.5 \leq m<1.25\end{array}$ & $\begin{array}{l}\text { If the degradation rate is kept } \\
\text { very low }(<0.3 \%) \text { higher } \\
\text { clearance rates allowed with a } \\
\text { low multiplier }(<1.25) \text {, but a } \\
\text { greater proportion of clearing } \\
\text { requires offsets. }(>0.35) \text {. }\end{array}$ \\
\hline 6 & $0.015 \leq d \leq 0.02^{*}$ & The degradation rate can reach \\
\hline
\end{tabular}




$\begin{array}{lll}\text { prob }=0.68 & 0.65 \leq p \leq 1^{*} & \text { its maximum value of } 2 \% \text { per } \\ \text { vol }=0.010 & 2.25 \leq m \leq 4^{*} & \text { year with high clearance rates } \\ 42.5 \leq c \leq 75^{*} & \text { but a high multiplier }(\geq 2.25) \\ & \text { is needed and the proportion } \\ & \text { of cleaning requiring offsets } \\ & \text { must be }>0.65 .\end{array}$

\section{Figures}

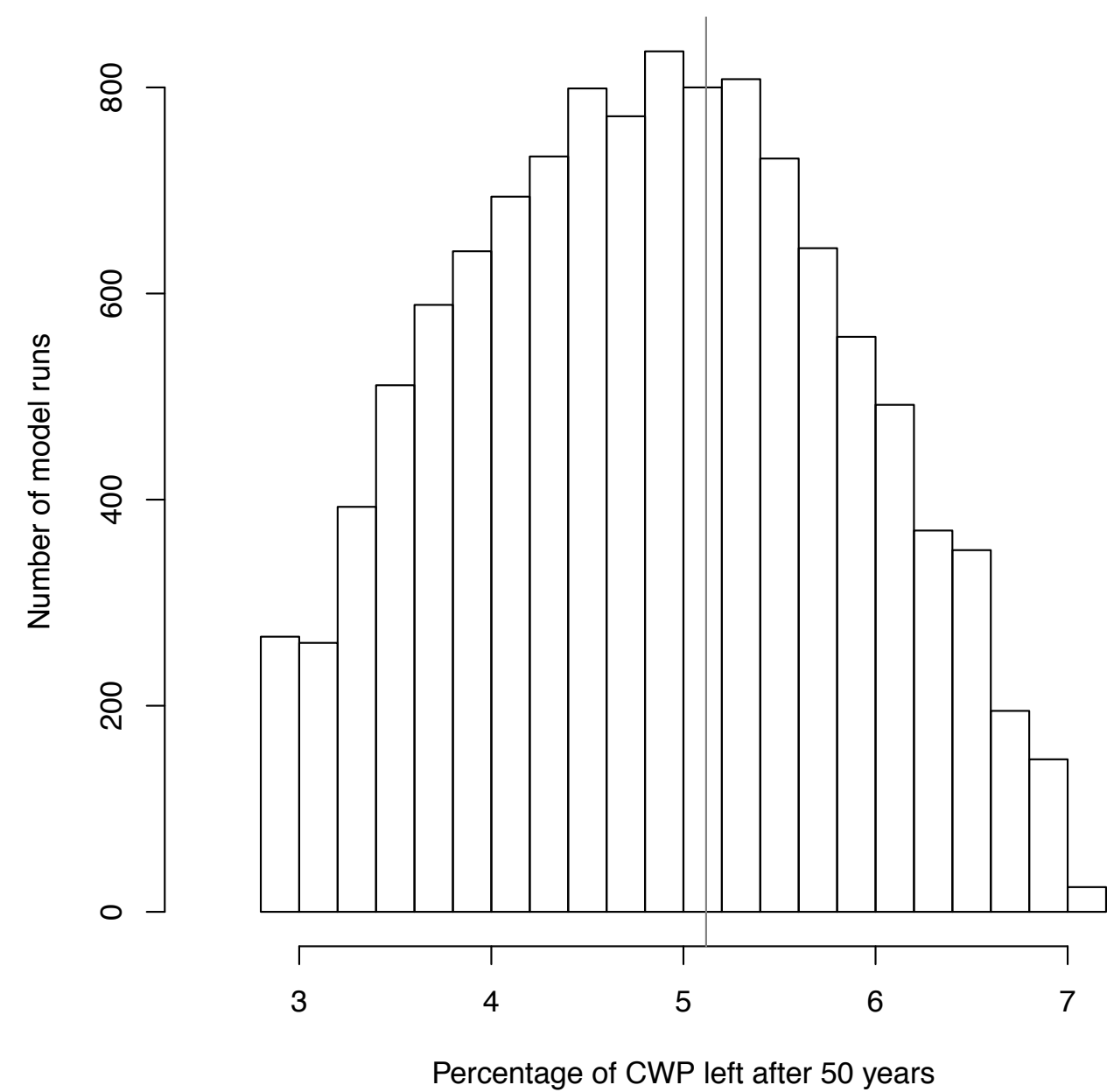

Fig. 1. Histogram summarizing the results of the CPW model. The horizontal axis is the proportion of the estimated original extent of CPW remaining (compared to the pre-1750 CPW estimated extent). The vertical axis shows the proportion of model runs that result in a given proportion of CPW remaining. The grey vertical line represents target used in the backcasting analysis for retaining at least $5.1 \%$ of the original CPW extent ( $60 \%$ of the current extent). 


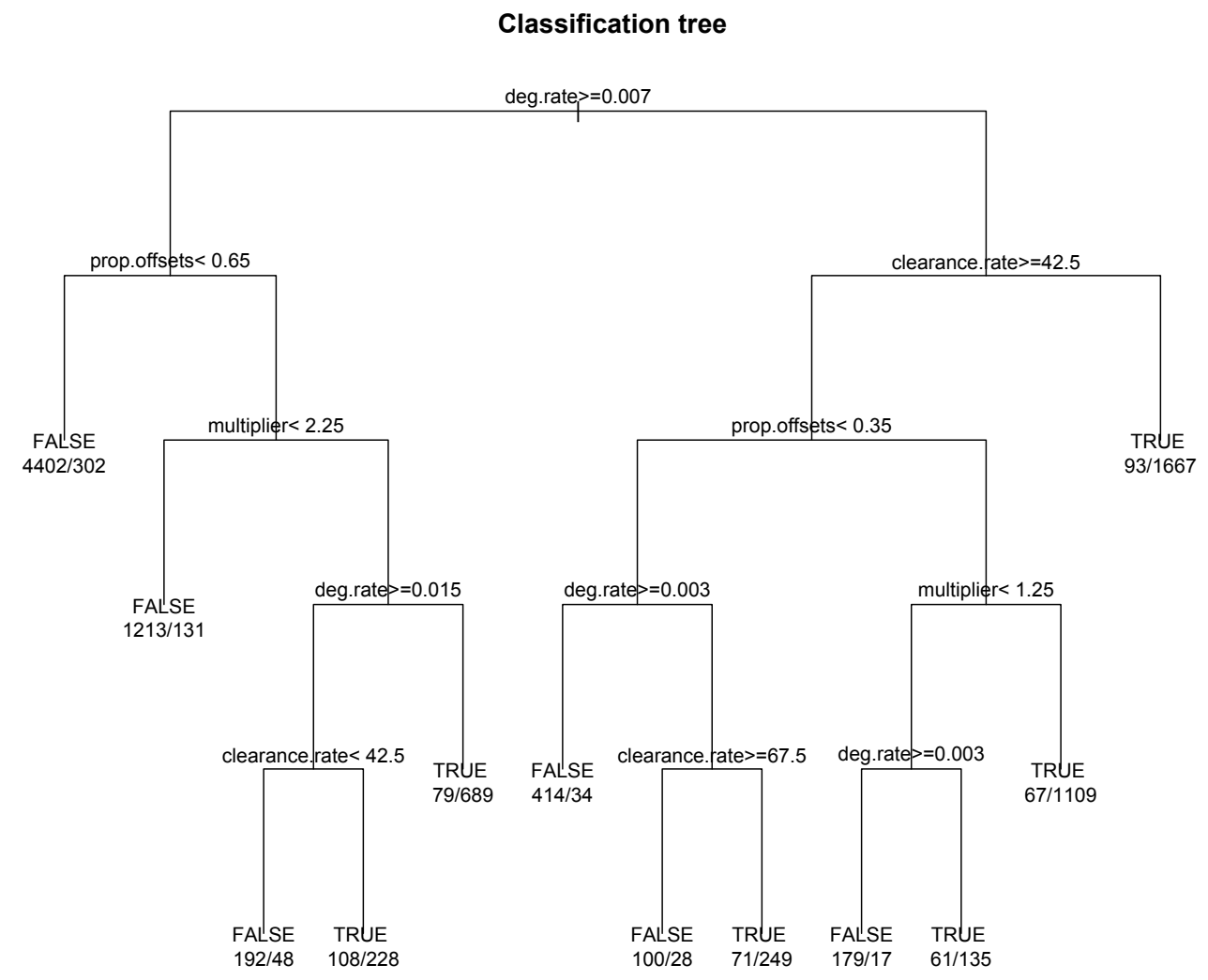

Fig. 2. Results of the classification tree analysis. The inequality rule applied to a single variable is show for each split. The right (left) hand side if each split represents the path taken if the inequality is met (fails). The terminal nodes are labeled either TRUE or FALSE depending on whether the rules leading to that node result in runs predominantly meeting or falling short of the target, respectively. As the classification is not perfect, the number of runs that fail or succeed to meet the TRUE or FALSE status is shown below each node. The first number indicates the number of runs that fail to meet the target and the second represents the number that succeed. 


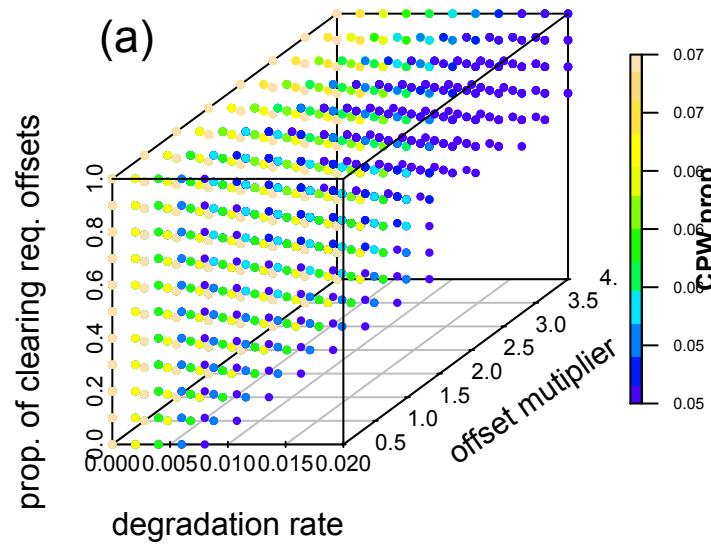

Policy rule 3

* $20<$ clearance rate $<75$ *

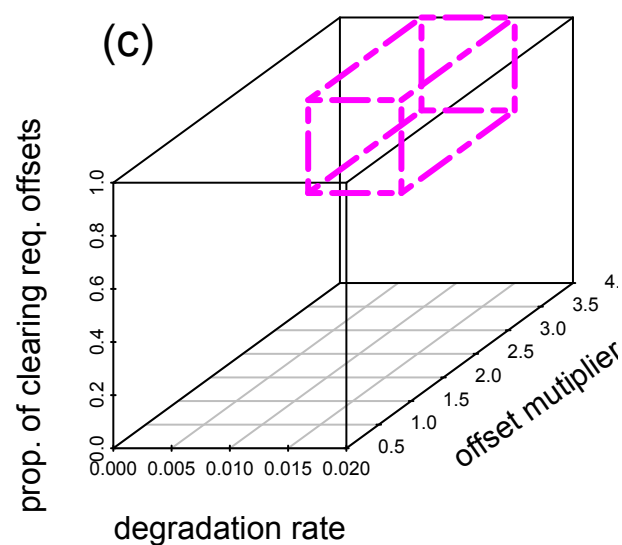

(b)

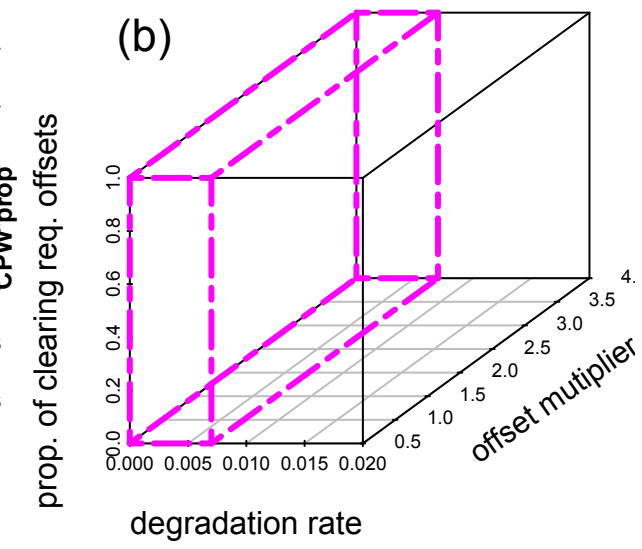

Policy rules 5 and 6 $42.5<$ clearance rate $<75$ *

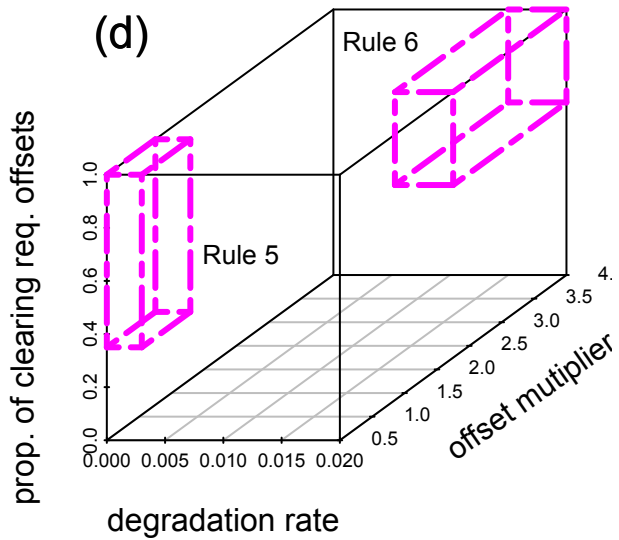

Fig. 3. Policy options resulting from the backcasting analysis. (a) All points in ensemble $S$. Each point represents a combination of parameter values that allow the future target to be met (colour coded by the amount of CPW predicted to remain in 50 years time). (b)-(d) Depictions of four of the six rule sets obtained using the classification tree analysis. Each rule set defines a 4-dimensional hypercuboid (the constraint on the fourth parameter is shown above the plot) with ${ }^{*}$ denoting no constraint as the maximum/minimal plausible value is used. 


\section{Supplementary Materials}

This document contains the supplementary materials for the manuscript:

Gordon, A. (2014) Implementing backcasting for conservation: determining multiple policy pathways for retaining future targets of endangered woodlands in Sydney, Australia. Biological Conservation. doi:

10.1016/j.biocon.2014.10.025

Appendix A

page 1

Appendix B .page 7

\section{Appendix A. \\ Further details of the predictive model for the future extent of CPW}

\section{A.1 Background}

The model incorporates the planned loss of the Cumberland Plain Shale Woodlands and Shale-Gravel Transition Forest ecological community (henceforth referred to as "CPW") through development inside two new Growth Centres for Sydney, Australia. The combined area of the two Growth Centres will provide residential and employment areas for approximately 500,000 people including approximately 181,000 dwellings at a range of dwelling densities (State of New South Wales, 2010). This will potentially result in the clearing of over 500 ha of CPW with associated biodiversity offsets (as described below) receiving protection and management (State of New South Wales, 2010). Although additional offsets are planned, it is possible they will not occur within the CPW ecological community but in other similar threatened grassy woodlands in wider Sydney bioregion. As the analysis presented here specifically focussed on the CPW ecological community, the additional offsets are not included.

In addition to the impacts from development in the Growth Centres, there are other processes impacting the remaining CPW. The model incorporates the most significant of these which comprises degradation of the community due primarily to invasive plant species such as the African Olive and African Love Grass (State of New South Wales, 2011) and both legal and illegal clearing of vegetation on private land outside the Growth Centres and the biodiversity offsets associated with legal clearing.

\section{A.2 Modelling the change in $C P W$ over time}

The model is deterministic and each time step implements the following steps: (i) the degradation process is applied to all CPW that is not in the protected of offset landuse category (see Table 1 in the manuscript); (ii) a check is made to determine if there is adequate $\mathrm{CPW}$ in appropriate landuse categories to undertake the clearing and offsets; (iii) if this check is successful, the clearing and offsets are implemented. At each time 
step (ii) and (iii) are applied separately for clearing inside and outside the Growth Centres and the associated offsets they generate.

\section{A.2.1 Clearing}

The clearance rates of CPW inside the Growth Centres were based on government estimates (State of New South Wales, 2010) and were assumed to be a fixed impact that occurs incrementally over 30 years (provided enough CPW remains in appropriate landuse categories, see Table A1). It is assumed there is no illegal clearing inside the Growth Centres. Outside the Growth Centres both legal and illegal clearing can occur. Legal clearing requires biodiversity offsets to be implemented while illegal clearing does not. Although the future rates of clearing are uncertain, a study undertaken in 2008 showed that $442 \pm 46$ ha of CPW had been lost over the nine years between 1998 and 2007 (NSW Scientific Committee \& Simpson, 2008). This averages to $48 \mathrm{ha} /$ year and it was suspected that a significant proportion of this was illegal clearing, although the actual extent was unknown (Table S1). Due to these uncertainties as well as the uncertainty in the extent to which historic rates will predict future legal and illegal clearing outside the Growth Centres, a range of different rates were explored in the model which were controlled by the parameters $c$ and $p$ (Table 2 in the manuscript).

\section{A.2.2 Biodiversity Offsets}

Once an area of CPW has been offset, it is assumed that the offset is managed effectively and continuously for the duration of the time period modelled and will never degrade to the point where it is no longer classified as CPW.

The biodiversity offsets from development within the Growth Centres occur both within and outside the growth centres. For each parcel to be developed, half of the CPW is required to be retained to count towards the offset while, an additional area of CPW is also required to meet the condition that the offset must be twice the area of the CPW cleared. This additional area of offset is implemented outside the Growth Centres. In addition 518 ha of CPW will be included as offsets within the Growth Centres to comply with the NSW State Environmental Planning Policy (SEPP) (State of New South Wales, 2006).

When legal clearing occurs outside the Growth Centres, the biodiversity offsets resulting from this clearing are only implemented outside the Growth Centres. All land outside the Growth Centres that is not Protected or Secured (Table 1) is in both the Developable/Offsettable landuse category (Table 1 in the manuscript) meaning CPW in these areas can be either developed or offset. The variable $m$ (Table 1 in the manuscript) controls the offset multiplier used for legal clearing that is not associated with the Growth Centres. The multiplier $m$ varies from 0.5 to 4 (Table 2 in the manuscript). The offset multipliers less than 2 represent the case where offsets are poorly implemented and fail to provide management and/or protection to their specified areas. Values of up to 4 were also explored for the offset multiplier to determine how larger multipliers could be used to compensate for higher levels of illegal clearing or higher degradation rates.

\section{A.2.3 Summary of development and offset rates}

Below the clearance and offset rates used in the model are summarised: 
- Clearance inside the Growth Centres Occurs at a rate of 19.8 ha per year for 30 years or until no CPW in the Developable landuse category is remains.

- Clearance outside the Growth Centres Both the rate of legal and illegal clearing is given by the parameters $c$ and $p$ (Table 3 ). The legal clearing rate is given by $p \times c$ and the illegal clearing rate is given by $(1-p) \times c$.

- Offsets inside Growth Centres Occurs at 17.3 ha per year for 30 years (resulting in a total of 518 ha which is provided as part of the NSW SEPP). As long as development inside the Growth Centres continues, an addition 19.8 ha of offsets per year are implemented as half of the offsets required for this development under the Environment Protection Biodiversity Conservation (EPBC) Act (Commonwealth of Australia, 1999).

- Offsets outside Growth Centres

i. 19.8 ha per year as the second half of the offsets required for development inside the GC under the EPBC Act.

ii. Offsets from legal clearing outside growth centres where area of $\mathrm{CPW}$ offset each time step is given by $m \times p \times c$ (see Table 2 in the manuscript).

\section{A.2.3 Further details on the equations in the manuscript}

Equations 1 and 2 in the manuscript have been simplified for readability and the full versions of these equations are presented below.

Including the full set of constraints for equation 1, which determines the area developed outside the growth centres, results in

$A_{t}^{\text {dev }, \text { oGC }}=\left\{\begin{array}{ll}c=p \times c+(1-p) \times c, & \left(A_{t}^{\text {developable }, \text { G } C} \geq c\right) \wedge\left(A_{t}^{\text {offsetable }, O G C} \geq m \times p \times c\right) \\ 0, & \left(A_{t}^{\text {developable }, \text { } G C}<c\right) \vee\left(A_{t}^{\text {offsetable }, O G C}<m \times p \times c\right)\end{array}\right.$,

where $\wedge$ represents logical "AND" and $\vee$ represents logical "OR". This implies clearing can only occur outside the Growth Centres if (i) there is enough CPW in the developable land use category outside the Growth Centres; and (ii) there is enough $\mathrm{CPW}$ in the offsettable land use category to implement offsets for the component of the clearing that is legal $(p \times c)$.

Development can only occur inside the Growth Centres over the first 30 years if there is enough CPW in the developable land use category inside the Growth Centres for the development, and that there is enough land in the offsettable land use category both inside and outside the Growth Centres. This constraint is labelled $C$ and can be expressed as

$(t \leq 30 \mathrm{yrs}) \wedge\left(A_{t}^{\text {developable } i G C} \geq 19.8\right) \wedge\left(A_{t}^{\text {offsetable }, i G C} \geq 17.3\right) \wedge\left(A_{t}^{\text {offsetable,oGC }} \geq 19.8\right)$

The full expression for equation 2 in the manuscript, for development inside the Growth centres, is then given by

$A_{t}^{\text {dev }, i G C}= \begin{cases}19.8 \text { ha/year, } & (C \text { is True }) \\ 0, & (C \text { is False })\end{cases}$ 
where $C$ is the defined by equation $\mathrm{A} 2$.

These constraints imply that for high levels of degradation, the development and/or offset targets sometimes cannot be met due to the amount of CPW being lost from degradation. In these cases a point is reached within 50 years where all the CPW is "locked up" - either developed, offset, in protected areas or degraded away. At this stage there is no further CPW available for development or offsetting and all activity ceases. This point can occur at different times inside and outside the Growth Centres. The point at which this occurs is sensitive to the degradation rate but can occur within 30-50 years when the degradation rate is high (dependant on other parameters). 
Table A1. Further details of the four policy parameters. The table includes the best estimate for each parameter, the ranges over which they are varied, and the step sizes used.

\begin{tabular}{|c|c|c|c|c|}
\hline $\begin{array}{l}\text { Parameter } \\
\text { (symbol) }\end{array}$ & $\begin{array}{l}\text { Plausible } \\
\text { ranges } \\
\text { and step } \\
\text { size }\end{array}$ & $\begin{array}{l}\text { Number } \\
\text { of } \\
\text { values }\end{array}$ & $\begin{array}{l}\text { Best } \\
\text { estimate }\end{array}$ & Comment \\
\hline $\begin{array}{l}\text { Degradation } \\
\text { rate }(d)\end{array}$ & $\begin{array}{l}0-0.02 \\
\text { (proportion } \\
\text { of CPW) } \\
\text { in steps of } \\
0.002\end{array}$ & 11 & $\begin{array}{l}\text { Uncertain, } \\
\text { but } \\
\text { degradation } \\
\text { is known to } \\
\text { be } \\
\text { occurring }\end{array}$ & $\begin{array}{l}\text { It is estimated that the } \\
\text { degradation rate is } \\
\text { somewhere between } 0 \text { to } \\
2 \% \text { of the CPW being } \\
\text { lost each year. }\end{array}$ \\
\hline $\begin{array}{l}\text { Clearance rate } \\
\text { (c) }\end{array}$ & $\begin{array}{l}20-75 \text { ha } \\
\text { /year in } \\
\text { steps of } 5 \\
\text { ha/year }\end{array}$ & 12 & 48 ha /year & $\begin{array}{l}\text { This is clearance of } \\
\text { vegetation outside the } \\
\text { Growth Centers (both } \\
\text { legal and illegal). The } \\
\text { best estimate is from a } \\
\text { historical analysis } \\
\text { (NSW Scientific } \\
\text { Committee \& Simpson, } \\
\text { 2008). }\end{array}$ \\
\hline $\begin{array}{l}\text { Proportion of } \\
\text { clearing } \\
\text { requiring } \\
\text { offsets }(p)\end{array}$ & $\begin{array}{l}0-1 \\
\text { in steps of } \\
0.1\end{array}$ & 11 & $\begin{array}{l}\text { Unknown, } \\
\text { but illegal } \\
\text { clearing is } \\
\text { known to } \\
\text { be } \\
\text { occurring }\end{array}$ & $\begin{array}{l}\text { This is the probability } \\
\text { that an offset is required } \\
\text { outside for clearing } \\
\text { outside the Growth } \\
\text { Centers. This is } \\
\text { measuring the } \\
\text { proportion of clearing } \\
\text { that is legal }(p) \text {. The } \\
\text { proportion that is illegal } \\
\text { is given by }(1-p) \text {. }\end{array}$ \\
\hline $\begin{array}{l}\text { Offset } \\
\text { multiplier }(m)\end{array}$ & $\begin{array}{l}0.5-4 \\
\text { in steps of } \\
0.5\end{array}$ & 8 & 2 & $\begin{array}{l}\text { The multiplier used } \\
\text { when calculating the } \\
\text { offset area for clearing } \\
\text { outside the Growth } \\
\text { Centers. The best } \\
\text { estimate of } 2 \text { comes } \\
\text { from the expected } \\
\text { implementation of the } \\
\text { EPBC Act. }\end{array}$ \\
\hline
\end{tabular}


Table A2. The initial area of CPW in each of the landuse categories used in the model. Outside the Growth Centres, all CPW that was not Protected or Secured was assumed be on private land can be either cleared or offset.

\begin{tabular}{cll}
\hline \hline & Landuse category & Area of CPW (ha) \\
\hline & Undevelopable & 116 \\
Inside Growth & Protected & 270 \\
Centres & Secured & 0 \\
& Offsettable & 493 \\
& Developable & 1159 \\
\hline \multirow{2}{*}{ Outside Growth } & Protected & 1986 \\
Centre & Secured & 917 \\
& Developable/ & 5270 \\
\hline \hline
\end{tabular}

\section{References}

Commonwealth of Australia. (1999). Environment Protection and Biodiversity Conservation Act. Available from http://www.environment.gov.au/epbc/. Accessed 23 September 2013.

NSW Scientific Committee, \& Simpson, C. (2008). Change in the distribution of Cumberland Plain Woodland. Unpublished Report.

State of New South Wales. (2006). State Environmental Planning Policy (Sydney Region Growth Centres) 2006. Avaiable from http://www.legislation.nsw.gov.au/viewtop/inforce/epi+418+2006+cd+0+N/. Accessed 25 September.

State of New South Wales. (2010). Sydney Growth Centres Strategic Assessment Program Report. Available from http://www.environment.gov.au/epbc/notices/assessments/pubs/sydney-growthcentres-program-report.pdf. Accessed 24 July 2013.

State of New South Wales. (2011). Cumberland Plain Recovery Plan (p. 48). Available from http://www.environment.nsw.gov.au/resources/threatenedspecies/20100501Cum berlandPlain.pdf. Accessed 13 June 2013. 


\section{Appendix B \\ Data and source code to generate all figures in the paper}

The R scripts and data to create the three plots in the paper are available for download from figshare (http://figshare.com/) via the link listed below.

Steps for downloading the data and R scripts to reproduce all figures in the paper:

1. Make sure $\mathrm{R}$ is installed. It can be downloaded from http://www.r-project.org/.

2. The following $\mathrm{R}$ libraries will need to be installed to run the $\mathrm{R}$ scripts to generate the figures:

- rpart, scatterplot3d, raster

- These libraries can be installed with the R command:

install.packages (c("rpart", "scatterplot3d", "raster"), repos = ' http: //cran.r-project.org' )

3. Download the R source code and data from Figshare via the following URL http://figshare.com/articles/R_scripts_and_data to_create the figures_for the Gordon 2014 backcasting paper_in Biological_Conservation/1250439 (the file is $2.2 \mathrm{meg}$ ).

4. Unzip the file, and set the R working directory to be the directory created when file was unzipped (it should be called "R-code-and-data-figs-forbackcasting-paper").

5. Then to create the 3 figures in the paper the following three scripts can be run in $\mathrm{R}$ by entering the following commands:

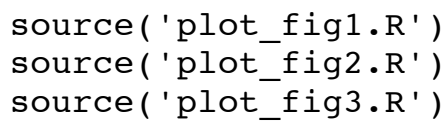

6. See the README.txt file contained in the zip file downloaded from Figshare for more information. 